\title{
OPTIMISATION OF SLUDGE LINE MANAGEMENT TO ENHANCE PHOSPHORUS RECOVERY IN WWTP
}

\author{
N. Marti ${ }^{\mathrm{a}}$, J. Ferrer ${ }^{\mathrm{b}}$, A. Seco ${ }^{\mathrm{a}}$, A. Bouzas ${ }^{\mathrm{a} *}$
}

5

\author{
a Dpto. Ingeniería Química. Universidad de Valencia. Doctor Moliner 50. 46100. Burjassot. Valencia. Spain. \\ b Instituto de Ingeniería del Agua y Medio Ambiente. Universidad Politécnica de Valencia. Camino de Vera s/n. \\ 46022. Valencia. Spain. \\ *Corresponding author. Tel.:+34-963544541; fax:+34-963544898; e-mail address: alberto.bouzas@uv.es (A. Bouzas)
}

\begin{abstract}
The management of the sludge treatment line can be optimized to reduce uncontrolled phosphorus precipitation in the anaerobic digester and to enhance phosphorus recovery in WWTP. In this paper, four operational strategies, which are based on the handling of

15 the prefermented primary sludge and the secondary sludge from an EBPR process, have been tested in a pilot plant. The separated or mixed sludge thickening, the use of a stirred contact tank and the elutriation of the thickened sludge are the main strategies studied. Both the reduction of phosphorus precipitation in the digester as well as the supernatant suitability for a struvite crystallization process were assessed in each 20 configuration. The mixed sludge thickening combined with a high flowrate elutriation stream reduced the phosphorus precipitation in the digester by $46 \%$, with respect to the separate sludge thickening configuration (common practice in WWTP). Moreover, in this configuration, $68 \%$ of the soluble phosphorus in the system is available for a possible phosphorus recovery process by crystallization (not studied in this work).

25 However, a high $\mathrm{Ca} / \mathrm{P}$ molar ratio was detected in the resultant supernatant which is pointed out as a problem for the efficiency of struvite crystallization.
\end{abstract}




\section{Keywords}

Anaerobic digestion, phosphorus, precipitation, sludge treatment, struvite, wastewater

\section{Nomenclature}

5 ACP Amorphous calcium phosphate

ALKP $\quad$ Bicarbonate alkalinity

ALK $_{\mathrm{T}} \quad$ Total alkalinity

HAP Hydroxyapatite

m Sludge mass flowrate

10 MAP Struvite

$\mathrm{NH}_{4}-\mathrm{N} \quad$ Ammonia nitrogen

OLR Organic Loading Rate

PAO Polyphosphate Accumulating Organisms

MP Mixing power

$15 \quad \mathrm{PO}_{4}-\mathrm{P} \quad$ Orthophosphate

PP Potential Phosphorus

PPS Prefermented Primary Sludge

SGP Specific gas production

SRT Solid retention time

20 TCOD Total chemical oxygen demand

TP Total phosphorus

TS Total solids

TVS Total volatile solids

VFA Volatile fatty acids

25 WP Mass of phosphorus per mass of treated sludge 
Q Volumetric flowrate

\%P-MAP Percentage of phosphorus fixed as MAP

\%P-HAP Percentage of phosphorus fixed as HAP

\%P-ads Percentage of phosphorus adsorbed

\section{Subscripts}

$\begin{array}{ll}\text { av } & \text { available } \\ \text { elut } & \text { elutriation } \\ \text { fix } & \text { fixed } \\ \text { lost } & \text { lost } \\ \text { ORGrel } & \text { release from organic matter degradation } \\ \text { PAOrel } & \text { release from Poly-P hydrolysis } \\ \text { prec } & \text { precipitated } \\ \text { rem } & \text { removal } \\ \text { TOTrel } & \text { total release }\end{array}$




\section{Introduction}

Eutrophication of water bodies caused by an increased input of inorganic phosphorus is a major worldwide problem (de-Bashan and Bashan, 2004). Among the different methods developed, the enhanced biological phosphorus removal process (EBPR)

5 appears as a feasible technology to remove phosphorus in wastewater treatment plants (WWTP). In contrast to conventional plants, the phosphorus content of activated sludge in EBPR processes reaches values of up to 7\% (Jardin and Pöpel, 1994) due to polyphosphate (Poly-P) storage by polyphosphate accumulating organisms (PAO).

10 On the other hand, phosphorus recovery and reuse has become important in recent years since phosphorus is a limited resource. After human consumption, most of the phosphorus remains in wastewaters. For this reason, phosphate recovery from wastewaters is considered to be a suitable method to promote phosphorus recycling.

15 In the sludge treatment line, especially in the anaerobic digestion process, phosphorus from Poly-P hydrolysis and from organic matter degradation is released, increasing the orthophosphate content in the system and, therefore, the potential for phosphorus precipitation. The concentration of other ions such as ammonium, potassium and magnesium also increases in the digester. Furthermore, the hardness of influent wastewater also controls precipitation processes of phosphorus inside the digester since it determines $\mathrm{Ca}^{2+}$ and $\mathrm{Mg}^{2+}$ concentrations in the wastewater.

According to the literature (Wild et al., 1997), different phosphate compounds are likely to precipitate in the sludge treatment system causing significant operational problems

25 that lead to an increase in maintenance costs. Accumulation of struvite 
$\left(\mathrm{MgNH}_{4} \mathrm{PO}_{4} .6 \mathrm{H}_{2} \mathrm{O}\right)$ on pipe walls and equipment surfaces of anaerobic digestion and post-digestion processes has been reported as a frequent problem in the wastewater treatment industry (Ohlinger et. al., 1998; Parsons and Doyle, 2004). Struvite precipitation occurs when the combined concentrations of $\mathrm{Mg}^{2+}, \mathrm{NH}_{4}-\mathrm{N}$ and $\mathrm{PO}_{4}-\mathrm{P}$ 5 exceed the struvite solubility product. Since specification of these components is a $\mathrm{pH}$ function, struvite solubility also varies with $\mathrm{pH}$. As $\mathrm{pH}$ increases, struvite solubility decreases. Therefore, anaerobic digestion and post-digestion processes, which show a higher $\mathrm{pH}$ value than the previous stages of the wastewater treatment, are more susceptible to struvite formation.

Phosphorus precipitation in the sludge line also determines the dissolved phosphorus concentration in the return liquor stream, which causes variations that might affect the efficiency of the EBPR process. Therefore, in order to assure a successful nutrient removal process, recirculated liquors to the wastewater treatment should be treated.

Phosphorus recovery by struvite crystallization is one of the technologies developed for treating sludge digester liquors. The product obtained, struvite, is a valuable slowrelease fertiliser for agriculture and, hence, an economical benefit can be obtained. In order to guarantee $\mathrm{P}$ rich-streams and thereby to obtain a high struvite production in the crystallization process, the uncontrolled phosphorus precipitation in the digester should be reduced. Other factors, such as the calcium concentration in the crystallizer influent stream, can significantly affect the production of struvite (Pastor et al., 2007). Therefore, suitable characteristics of the supernatants treated by crystallization should be guaranteed. 
A simple methodology to assess phosphorus precipitation in anaerobic digesters based on routine experimental analysis and mass balances was developed in a previous work (Martí et al., 2007). This methodology was successfully applied in an anaerobic digestion pilot plant treating prefermented primary sludge and secondary sludge from an

5 EBPR process and in a full-scale WWTP in Murcia, Spain (Barat et al., 2008).

In this work, the above methodology has been applied to optimise sludge treatment line management in order to minimise uncontrolled phosphorus precipitation in the digester. Hence, operational costs associated to the formation of deposits can be reduced and the

10 phosphorus recovery can be enhanced. Four operational strategies, which are based on the management of the prefermented primary sludge and the secondary sludge from an EBPR process, were tested in a pilot plant.

\section{Materials and methods}

\section{$15 \quad$ 2.1. Anaerobic digestion pilot plant}

The anaerobic digestion pilot plant treats the prefermented primary sludge (PPS) generated in a fermentation/elutriation pilot plant and the waste activated sludge from an EBPR pilot-scale process (EBPR sludge). The three plants are located in the Carraixet WWTP, which is near the city of Valencia (Spain). A detailed description of

20 the anaerobic digestion pilot plant can be found in Martí et al., (2007).

\subsection{Process schemes}

The four operational configurations studied are based on the separated or mixed sludge thickening, the use of a contact tank, the elutriation of the thickened sludge and the flow

25 rate of the elutriation stream. Table 1 summarizes the main characteristics of each 
configuration. Figure 1 outlines the four operational configurations. The supernatants and centrates obtained in the different configurations described below were used in a phosphorus recovery process by struvite crystallization, which is not the aim of this work. The study performed in each configuration only considers the sludge treatment management and no crystallization results are presented. For that reason, this latter process is drawn with grey lines in Figure 1.

\subsubsection{Configuration C1: Separated thickening of sludges}

In this configuration (Figure 1a) the PPS (1) is directly pumped from the primary

10 settler/fermenter to the digester. No thickening of this prefermented sludge is carried out due to the high solid concentrations achieved in the primary settling tank. EBPR sludge (2) is wasted from the aerobic reactor of the EBPR system and pumped to the gravity thickener, where is settled and thickened. Once both sludges are mixed in the influent pipe (4), they are fed to the anaerobic digester. The digested sludge (5) is dewatered by

15 centrifugation and the centrate obtained is sent to the phosphorus recovery process by struvite crystallization.

\subsubsection{Configuration C2: Mixed thickening and sludge elutriation}

In this configuration (Figure 1b) PPS (1) and EBPR sludge (2) are pumped from the

20 primary settler/fermenter and the secondary settler respectively to the gravity thickener. PPS is thickened to provide a suitable contact and mixing with EBPR sludge. Elutriation of the soluble phosphorus is carried out by recirculation of the thickened sludge (4) from the thickener bottom to the inlet sludge zone. The thickener supernatant (3) is mixed with the centrate obtained in the digested sludge dewatering and directed to

25 the phosphorus recovery process by struvite crystallization. 


\subsubsection{Configuration C3: Contact tank previous the mixed thickening of sludges}

In order to increase the mix and contact time between the two sludges a stirred contact tank previous to the mixed thickening step is placed in the pilot plant (Figure 1c). PPS

5 (1) and EBPR sludge (2) are pumped to the contact tank. The retention time in the tank was set at 3.6 hours. Previous experiments showed that this retention time (3.6 h) was enough to enhance phosphorus released from Poly-P in the tank. The contact tank outlet stream is sent to the gravity thickener, where no elutriation of the thickened sludge takes place, and is afterwards digested as in the previous configurations. Both the thickener

10 supernatant (3) and the centrate of the digested sludge dewatering are sent to the phosphorus recovery process.

\subsubsection{Configuration C4: Mixed thickening with sludge high elutriation flowrate}

In this configuration (Figure 1d), PPS from the primary settler/fermenter (1) and EBPR

15 sludge from the aerobic reactor of the BNR system (2) are pumped to the thickener. Elutriation of the thickened sludge is also carried out, as previously described. Moreover, the EBPR sludge from the aerobic reactor is used as a "washing-stream" that enhances the thickened sludge elutriation. The thickened sludge (4) is digested and dewatered by centrifugation. The centrate obtained in the dewatering system and the thickener supernatant (3) are mixed and directed to the crystallization process.

\subsection{Experimental procedure}

The anaerobic digestion process was operated at mesophilic conditions ( $\left.\mathrm{T}=35 \pm 1^{\circ} \mathrm{C}\right)$ and at a solids retention time (SRT) of 20 days in all experiments. Table 2 provides a summary of the anaerobic digestion process for the four experiments carried out, 
including the operational parameters in the digester, the influent and effluent sludge characterization, and the anaerobic digestion results. The organic loading rate (OLR), the mass flowrate of sludge fed to the digester (m), and the percentage of primary and secondary sludge in the total sludge fed to the digester (\%PPS and \%EBPR,

5 respectively) depend on the operation of the fermentation/elutriation and the EBPR processes. The elutriation flowrate (Qelut) was maintained at $12 \mathrm{l} \mathrm{d}^{-1}$ and $15 \mathrm{l} \mathrm{d}^{-1}$ for configurations C2 and C4, respectively.

\subsection{Analytical methods}

10 Total solids (TS), total volatile solids (TVS), total COD (TCOD), total phosphorus (TP), and total alkalinity $\left(\mathrm{ALK}_{\mathrm{T}}\right)$ were performed in accordance with the Standard Methods (APHA, 2005). Volatile fatty acids concentration (VFA) and bicarbonate alkalinity $\left(\mathrm{ALK} \mathrm{P}_{\mathrm{P}}\right)$ were measured using the 5-point titration method (Moosbrugger et al., 1992). $\mathrm{PO}_{4}-\mathrm{P}, \mathrm{NH}_{4}-\mathrm{N}$, and soluble calcium, magnesium and potassium were

15 analysed by ion chromatography (Metrohm IC, Switzerland).

Biogas composition $\left(\mathrm{CO}_{2}, \mathrm{~N}_{2}\right.$, and $\left.\mathrm{CH}_{4}\right)$ was analyzed by gas chromatography separation (6890N Agilent Technologies, USA) with 2 capillary columns (HP- PLOT Molesieve and HP- PLOT Q) and thermal conductivity detector (TCD). Injector and detector temperatures were fixed at $110^{\circ} \mathrm{C}$ and $25^{\circ} \mathrm{C}$, respectively. Oven temperature was maintained at $40^{\circ} \mathrm{C}$ for 12.5 minutes. The carrier gas was $\mathrm{He}$ and the flow rate used was constant at $4 \mathrm{ml} \mathrm{min}^{-1}$. 


\subsection{Calculation of phosphorus precipitation and potential phosphorus for crystallization}

$\mathrm{PO}_{4}-\mathrm{P}, \mathrm{Ca}^{2+}, \mathrm{Mg}^{2+}$, and $\mathrm{K}^{+}$mass balances were carried out to assess phosphorus precipitation in the digester using the methodology developed in Martí et al. (2007). As

5 explained in that work, $\mathrm{PO}_{4}-\mathrm{P}, \mathrm{K}^{+}$and $\mathrm{Mg}^{2+}$ are released during sludge anaerobic digestion due to polyphosphate hydrolysis and organic matter degradation, whereas $\mathrm{Ca}^{2+}$ is considered to be released only due to organic matter degradation. The organic content of phosphorus, potassium, magnesium and calcium in the mixed influent sludge was calculated using the proportion of PPS (\%PPS) and EBPR sludge (\%EBPR) in each

10 experiment (Table 2) and the content of each element in the organic matter (Martí et al., 2007).

In order to confirm the precipitates formed in the digester conditions, the Saturation Index values (SI) for the precipitates considered were calculated. The SI is used to

15 describe the saturation state of the aqueous phase composition versus different solids (Eq. 1). When SI $=0$, the solution is in equilibrium; when $\mathrm{SI}<0$, the solution is undersaturated and no precipitation occurs; when SI $>0$, the solution is supersaturated and precipitation occurs spontaneously. Therefore, the SI values can be used to evaluate the effect of the solution composition on the tendency and extent of the precipitation, 20 according to the following equation:

$$
\mathrm{SI}=\log \frac{\mathrm{IAP}}{\mathrm{K}_{\mathrm{SP}}}
$$

where IAP represents the ion activity product, and $\mathrm{K}_{\mathrm{SP}}$ represents the thermodynamic solubility product. 
The potential phosphorus (PP), which represents the phosphorus that can be recovered in the crystallization process with regard to the maximum phosphorus available in the sludge treatment system, was also calculated. The PP value in each configuration was evaluated as follows:

$$
P P(\%)=\frac{w_{P A V}}{w_{P A V}+w_{P L O S T}} \cdot 100=\frac{w_{P A V}}{w_{P \text { TOT }}} \cdot 100
$$

5

where: $\quad$ WP Av: g of phosphorus available per kg of treated sludge WP LOST: g of phosphorus lost per kg of treated sludge WP тот: g of phosphorus available in the system per kg of treated sludge

\section{Results}

\subsection{Anaerobic digestion}

The digester influent and effluent sludge characteristics are shown in Table 2. The data included in these tables represent the average value of each parameter once the stationary conditions (a minimum of two times the SRT) were reached. The standard deviation (s.d.) is also included. As Table 2 shows, differences in the influent sludge characteristics can be observed among the four configurations tested. As stated above, the anaerobic digestion pilot plant treats the PPS and the EBPR sludge from the two other pilot plants located in the Carraixet WWTP. Therefore, the digester influent sludge is widely influenced by the operation of the previous wastewater treatment processes. Moreover, the variability of the influent wastewater also affects operation of the pilot plants.

The results obtained in the anaerobic digestion process confirm that the four

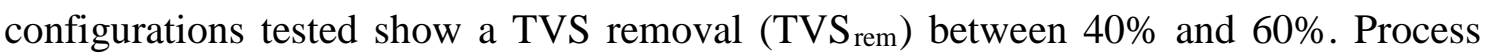


stability in the digester was assessed by means of $\mathrm{pH}$, VFA and alkalinity measurements in the reactor. The $\mathrm{pH}$ evolution was continuously monitored showing values around $7.0 \pm 0.2$ in the four experiments. With regard to the VFA concentration in the digester, a wide variability for the different configurations was obtained, reaching high values in

5 configurations C3 and C4. The ratio between the alkalinity associated with the VFA (calculated as the difference between total alkalinity and bicarbonate alkalinity) and the total alkalinity, ALK $\mathrm{VFA}_{\mathrm{A}} / \mathrm{ALK}_{\mathrm{T}}$, was lower than 0.25 in all the experiments.

\subsection{Precipitation assessment in the anaerobic digester}

10 The results obtained from the mass balances application in each configuration studied are shown in Table 3. The highest concentration of fixed phosphorus $\left(\mathrm{P}_{\text {fix }}\right)$ was obtained in configuration $\mathrm{C} 1$ due to the great concentration of available phosphorus $\left(\mathrm{P}_{\mathrm{av}}\right)$ that was achieved in this configuration. As Table 3 shows, in this configuration, $403.4 \mathrm{mg} \mathrm{l}^{-1}$ of phosphorus precipitated in the anaerobic digester. The mixed thickening of both

15 sludges and the elutriation of the resulting thickened sludge (configuration C2) made it possible to reduce the phosphorus release in the digester, which led to a decrease in the fixed phosphorus. The introduction of a stirred contact tank (configuration C3) slightly reduced the phosphorus fixation. Finally, the configuration C4 made it possible to reduce the phosphorus fixation in the digester by $43 \%$ compared with the separated thickening configuration.

The magnesium release in the digester is due to both the Poly-P hydrolysis and the organic matter degradation. As observed with phosphorus, the magnesium released associated to Poly-P hydrolysis (MgPaOrel) was significantly reduced in configuration 
C4 giving rise to the lowest precipitation of magnesium in the digester. With regard to calcium precipitation, the highest value was achieved in configuration C1.

\subsection{Precipitates formed in the anaerobic digester}

5 The most common salts found in anaerobic digesters are phosphates and carbonates of calcium and/or magnesium. In this work, magnesium has been considered to precipitate in the digester mainly as struvite, making it possible to estimate the amount of phosphate precipitated as struvite (\%P-MAP) from its stoichiometry. The calcium that precipitated in the digester was considered to be in the form of hydroxyapatite (HAP).

10 Thus, the amount of phosphate precipitated with calcium (\%P-HAP) was calculated using a molar ratio $\mathrm{Ca} / \mathrm{P}$ of 1.67 . The precipitation of aluminium and iron phosphates was not considered in this work due to the negligible soluble iron and aluminium concentrations in the digester influent and effluent streams. Therefore, the rest of the phosphorus fixed in the digester was considered to be adsorbed on the surface of solids 15 (\%P-ads).

According to these considerations, the phosphorus fixed in the digester as struvite (\%PMAP), as hydroxyapatite (\%P-HAP) or adsorbed on solid surfaces (\%P-ads) has been estimated for the four configurations. The results obtained and the molar ratios $\mathrm{Mg} / \mathrm{P}$, $\mathrm{Mg} / \mathrm{Ca}$ and $\mathrm{Ca} / \mathrm{P}$ in the digester are shown in Table 4. As this table shows, the highest percentage of phosphorus fixed as MAP is obtained in configuration C2, in agreement with the highest $\mathrm{Mg} / \mathrm{Ca}$ molar ratio and the lowest $\mathrm{Ca} / \mathrm{P}$ molar ratio. The highest percentage of phosphorus fixed as HAP is achieved in C4 in agreement with the highest $\mathrm{Ca} / \mathrm{P}$ molar ratio. In all the experiments, the main phosphorus precipitate that formed is struvite. 
The Saturation Index values (SI) have been calculated for the precipitates considered and they are shown in Table 5. For the four configurations, the digester sludge composition is supersaturated with regard to MAP, HAP and its precursor ACP, which

5 confirms the possible formation of these precipitates in the digester. With regard to potassium struvite formation, the results obtained show that the solution is undersaturated at the conditions achieved in the digester, which proves that no potassium struvite precipitates. Moreover, the presence of MAP in solid deposits found in the outgoing digester pipe was confirmed by means of XRD analysis (Figure 2).

\subsection{Potential phosphorus for the struvite crystallization process.}

In order to quantify the phosphorus that could be recovered in a crystallization process, the loss of $\mathrm{PO}_{4}-\mathrm{P}$ in any stage of the sludge treatment system and the available $\mathrm{PO}_{4}-\mathrm{P}$ in the supernatant and centrate produced were both calculated for each configuration. In order to compare the results among the different configurations, the results were calculated considering the mass flowrate of sludge fed to the digester.

Two P-rich streams can be treated by struvite crystallization: the centrate from the digested sludge dewatering and the thickener supernatant. Table 6 shows the average

20 values of the volumetric flowrate (Q) and the $\mathrm{PO}_{4}-\mathrm{P}$ concentration for both streams. The volumetric flowrate in the digester effluent is reduced by a factor of $4 / 6$ in the dewatering system, whereas the $\mathrm{PO}_{4}-\mathrm{P}$ concentration does not undergo significant variations. With regard to the thickener supernatant, important differences in both Q and $\mathrm{PO}_{4}-\mathrm{P}$ values can be observed. These differences can be attributed to the operational characteristics of each configuration. 
In the sludge treatment line, phosphorus losses may occur in the anaerobic digester due to precipitation as different phosphate salts, and always occurs in the dewatering process where part of the soluble phosphorus remains in the dewatered sludge.

The maximum phosphorus that could be recovered in a crystallization process with regard to the maximum phosphorus available in the sludge treatment system, (i.e. potential phosphorus, PP) is shown in Table 7. Configurations C1 and C3 show low PP values of around 20\%. Configuration C2 increases the PP value up to $37 \%$, and

10 configuration $\mathrm{C} 4$ shows the best results, reaching a PP value of $68 \%$.

\section{Discussion}

\subsection{Operation of the anaerobic digester}

As Table 2 shows, the VFA concentration in the digester shows a wide variability for

15 the different configurations tested, which can be related to the differences in the VFA concentration in the influent sludge. VFA in the digester inlet stream comes mainly from the PPS. Therefore, the operation of the primary sludge fermentation process determines the VFA concentration in the sludge that is fed to the digester. In this work, the ratio $\mathrm{ALK}_{\mathrm{VFA}} / \mathrm{ALK}_{\mathrm{T}}$ was below the maximum recommended values (i.e., 0.3-0.4) to ensure operational stability of the process (Lema et al., 1993).

With regard to the performance of the anaerobic digestion process, the four configurations tested show TVS $_{\text {rem }}$ values between $40 \%$ and $60 \%$, in agreement with the typical ones observed in anaerobic mesophilic digesters that treat mixed sludges (Grady et al., 1999). 
The specific gas production (SGP) measured in all the studied configurations is in agreement with the literature data observed when digesting primary and secondary sludges (Zhao and Viraraghavan, 2004). Biogas composition shows values between

$563 \%-65 \%$ of methane content in the four configurations, which is a typical value found for proper anaerobic digestion processes.

\subsection{Precipitation in the anaerobic digester}

The precipitation study in the anaerobic digester (Table 3) points out that the highest

$10 \mathrm{P}_{\text {fix }}$ was achieved for configuration $\mathrm{C}$, which can be explained by the highest $\mathrm{P}_{\mathrm{av}}$ in this configuration. The conventional configuration of a sludge treatment line (i.e., separate thickening of primary and EBPR sludge) does not enhance Poly-P hydrolysis in the thickener due to the lack of high VFA concentration, which is provided principally by primary sludge. Therefore, Poly-P hydrolysis takes place mainly in the

15 digester, which increases phosphate concentration and as a consequence, increases the potential for phosphorus precipitation inside the digester. The reduction of $\mathrm{P}_{\text {fix }}$ in configuration $\mathrm{C} 2$, with respect to configuration $\mathrm{C} 1$, has been attributed to a decrease in the phosphorus released in the digester. Both the presence of significant VFA concentrations from primary sludge in the thickener and the anaerobic conditions

20 achieved in it enhanced Poly-P hydrolysis. Thickened sludge recirculation favoured the elutriation of the released phosphorus and thus the phosphorus withdrawal from the digestion system. In configuration C3, the use of a stirred contact tank did not significantly reduce the Poly-P hydrolysis in the digester compared with configuration C2. Configuration C4 shows the lowest phosphorus precipitation in the digester. The mixed thickening of PPS and EBPR sludge combined with an elutriation system using 
an external stream of high flowrate reduced the available phosphorus in the digester. As Table 3 shows, only $11.1 \mathrm{mg} \mathrm{l}^{-1}$ of phosphorus was released in the digester from Poly-P hydrolysis, with the phosphorus release in the digester being due mainly to organic matter degradation.

Unlike magnesium ions, calcium ions do not play any role in the stabilization of the charge of Poly-P. Therefore, no release of calcium associated to Poly-P hydrolysis during anaerobic digestion is expected since organic matter degradation is the only mechanism for calcium release. The calcium available to precipitate in the digester is

10 mainly the soluble calcium concentration in the digester influent. Hence, both the hardness of the influent wastewater and the sludge handling prior to digestion determine the precipitation of calcium in the digester. Table 3 also shows that the highest calcium precipitation was achieved in configuration $\mathrm{C} 1$, which can be attributed to the highest soluble calcium concentration in the digester (influent + release from organic matter 15 degradation).

\subsection{Evaluation of the precipitates formed}

According to the literature, four possible phosphate magnesium salts can precipitate from a solution containing $\mathrm{Mg}^{2+}, \mathrm{NH}_{4}-\mathrm{N}$, and $\mathrm{PO}_{4}-\mathrm{P}$ (i.e., struvite $\left(\mathrm{MgNH}_{4} \mathrm{PO}_{4} \cdot 6 \mathrm{H}_{2} \mathrm{O}-\right.$ MAP); magnesium hydrogen phosphate trihydrate or newberyite $\left(\mathrm{MgHPO}_{4} \cdot 3 \mathrm{H}_{2} \mathrm{O}\right)$; and trimagnesium phosphate in two states of hydration $\left(\mathrm{Mg}_{3}\left(\mathrm{PO}_{4}\right)_{2} \cdot 22 \mathrm{H}_{2} \mathrm{O}\right.$ and $\left.\left.\mathrm{Mg}_{3}\left(\mathrm{PO}_{4}\right)_{2} \cdot 8 \mathrm{H}_{2} \mathrm{O}\right)\right)$. According to Martí et al. (2007), of these, struvite was considered the main precipitate formed in the digester at the experimental conditions existing in the four experiments. The XRD analysis (Figure 2) in the solids deposits found in the effluent digester pipe confirmed this point. As other studies show (Heinzmann and 
Engel, 2005), struvite formation is favoured in the anaerobic digestion and postdigestion processes, especially in high turbulence zones such as pipes, valves, etc., where the spontaneous release of carbon dioxide leads to a $\mathrm{pH}$ increase. Moreover, precipitation of magnesite $\left(\mathrm{MgCO}_{3}\right)$ has not been considered due to its high solubility

5 when compared to struvite. Different authors (Schuiling and Andrade, 1999; Wilsenach et al., 2006) have observed that potassium struvite $\left(\mathrm{KMgPO}_{4} \cdot 6 \mathrm{H}_{2} \mathrm{O}\right)$ could precipitate instead of MAP only in the case of low ammonium concentrations, which it is not the case in any of the experiments carried out. Therefore, magnesium can be considered to precipitate in the digester mainly as struvite, making it possible to estimate the amount 10 of phosphate precipitated as struvite (\%P-MAP) from its stoichiometry.

With regard to calcium precipitates, according to Martí et al. (2007), hydroxyapatite (HAP) was considered to be the calcium phosphate formed due to the high process retention time, which allows precursors (i.e., mainly amorphous calcium phosphate -

15 ACP) to transform into HAP. Calcite formation was not considered due to the high phosphate concentrations in the digester (Plant and House, 2002; Lin and Singer, 2005). The rest of the phosphorus fixed neither as MAP nor as HAP was considered to be adsorbed on the surface of solids (\%P-ads). Although phosphate adsorption during anaerobic digester is still not a well-understood process, it is considered to be a possible

20 mechanism for phosphorus fixation (Jardin and Pöpel, 1994; Wild et al., 1997).

\subsection{Evaluation of potential phosphorus for struvite crystallization}

The potential phosphorus (PP) defined in this work, indicates the efficiency of each configuration to guarantee available $\mathrm{PO}_{4}-\mathrm{P}$ in a struvite crystallization process. The low

25 PP value in configuration C1 (16\%), is a result of the high phosphorus precipitation in 
the digester and the low $\mathrm{PO}_{4}-\mathrm{P}$ mass flowrate value in the thickener effluent (Table 7), which made this stream not suitable for a crystallization process. Configuration C3 also shows a low PP value (18\%). Although phosphorus precipitation in the digester is slightly reduced in C3, the available phosphorus is very low principally in the thickener

5 supernatant. This result indicates that the use of a contact tank instead of the thickened sludge recirculation does not enhance the phosphorus extraction from the system, due to a possible phosphorus precipitation in the contact tank. Configuration C2 shows a high PP value with respect to the previous configurations due to a higher availability of phosphorus ( $\mathrm{WP} \mathrm{AV}$ ) in the thickener supernantant as well as in the dewatering system centrate. Nevertheless, the best results were obtained in configuration C4, with a PP value of $68 \%$, which is a consequence of the low phosphorus precipitation in the digester and the high phosphorus content in the thickener supernatant. Therefore, this latter configuration obtains the highest phosphorus availability for the crystallization system.

However, as Table 8 shows, the crystallizer inlet stream in configuration C4 has the highest $\mathrm{Ca} / \mathrm{P}$ molar ratio. This value is due to the high thickener supernatant flowrate produced as a consequence of using the EBPR sludge (i.e., not settled) as a "washingstream”. In fact, if the dewatering centrate and the thickener supernatant volumetric

20 flowrates are compared (i.e., $2.8 \mathrm{l} \mathrm{d}^{-1}$ vs $43.8 \mathrm{l} \mathrm{d}^{-1}$, respectively (Table 6)), it can be observed that the stream that would be feed to the crystallizer consists mainly of the thickener supernatant. Therefore, most of the calcium content in the wastewater is transferred to the crystallizer inlet stream, which, in this case, leads to a high molar ratio $\mathrm{Ca} / \mathrm{P}$. 
High calcium content in the crystallizer influent stream has pointed out as a detrimental influence on struvite formation during crystallization processes. Pastor et al. (2007) studied this effect in real supernatants showing a precipitation of calcium phosphates rather than struvite in the crystallizer. Thus, although configuration C4 decreases the

5 precipitation in the digester due to the high elutriation provided with the "washing stream”, the characteristics of the crystallizer inlet stream in this configuration could affect the struvite precipitation efficiency. For this reason, if the objective is to obtain struvite in the crystallization process, this strategy would not be the best one, especially if the water hardness is high, due to the high calcium content in crystallizer influent 10 stream.

Future investigations will focus in the phosphorus adsorption during anaerobic digestion and in the fate of phosphorus in the global wastewater treatment system.

\section{Conclusions}

In this paper, different operational strategies, which are based on the handling of the sludges produced in wastewater treatment, have been tested. The main conclusions are shown below:

- In the four configurations, the anaerobic digestion of PPS and EBPR sludge

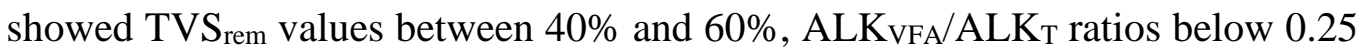
and typical values for biogas production and composition.

- MAP was found as the main precipitate that formed in the digester. The Saturation Index (SI) values confirm the possible formation of MAP, HAP and ACP and prove that potassium struvite does not precipitate at the studied conditions. Phosphorus adsorption on solid surfaces was also observed. 
- Phosphorus precipitation in the digester can be reduced using mixed thickening of PPS and EBPR sludge, and a high flowrate "washing-stream" in the thickener. With this operational strategy $68 \%$ of the soluble phosphorus in the system would be available for a crystallization process.

5 - The characteristics of the "washing stream" (flowrate and composition) will determine the thickener supernantant suitability for phosphorus recovery as struvite. For this reason, special attention must be paid to the $\mathrm{Ca} / \mathrm{P}$ molar ratio in waters with high levels of hardness.

\section{Acknowledgements}

This research work has been supported by the Spanish Research Foundation (MCYT, project PPQ2002-04043-C02-02), which is gratefully acknowledged. Technical support from Entidad Pública de Saneamiento de Aguas Residuales de la Comunidad Valenciana is also gratefully acknowledged.

\section{References}

APHA, 2005. Standard Methods for the Examination of Water \& Wastewater. $21^{\text {th }}$ ed. American Public Health Association, American Water Works Association and Water Environment Federation, Washington DC, USA.

Barat, R., Bouzas, A., Martí, N., Ferrer, J. and Seco, A. (2008) Precipitation assessment in wastewater treatment plants operated for biological nutrient removal: A case study in Murcia, Spain. Journal of environmental management. In press. doi:10.1016/j.jenvman.2008.02.001 
de-Bashan, L.E. and Bashan, Y. (2004) Recent advances in removing phosphorus from wastewater and its future use as fertilizer (1997-2003). Water Research 38 (19), 42224246.

5 Grady, C.P.L., Daigger, G.T. and Lim, H.C. (1999) Biological wastewater treatment. Second Edition, Marcel Dekker, Inc. New York. Basel.

Heinzmann, B. and Engel, G. (2005) Induced magnesium ammonia phosphate precipitation to prevent incrustations and measures for phosphate recovery. In

10 Proceedings Nutrient Management in Wastewater Treatment Processes and Recycle Streams, Krakow, Poland, September 19-21.

Jardin, N. and Pöpel, H.J. (1994) Phosphate release of sludges from enhanced biological P-removal during digestion. Water Science and Technology 20(6), 281-292.

Lema, J.M., Mendez, R. and Soto, M. (1993) Operation and control of anaerobic digesters (I). (Operación y control de digestores anaerobios (I)). Ingenieria Química. 294, 467-474.

20 Lin Y.P. and Singer P. C. (2005) Inhibition of calcite crystal growth by polyphosphates. Water Research 39 (19), 4835-4843.

Mamais, D., Pitt, P.A., Cheng, Y.W., Loiacono, J. and Jenkins, D. (1994) Determination of ferric chloride dose to control struvite precipitation in anaerobic sludge digester. 25 Water Environmental Research 66 (7), 912-918. 
Martí, N., Bouzas, A., Seco, A. and Ferrer, J. (2008) Struvite precipitation assessment in anaerobic digestion processes. Chemical Engineering Journal 141, 67-74.

5 Moosbrugger, R.E., Wentzel, M.C., Ekama, G.A. and Marais, G.v.R. (1992) Simple titration procedures to determine $\mathrm{H} 2 \mathrm{CO} 3$ alkalinity and short-chain fatty acids in aqueous solutions containing known concentrations of ammonium, phosphate and sulphide weak acid/bases. Water Research. Comission, Report No. TT 57/92. University of Cape Town, Research Report W 74. Pretoria, Republic of South Africa

Murray, K., May, P.M. (1996). Joint Expert Speciation System (JESS). An international computer system for determining chemical speciation in aqueous and non aqueous solution environmental. Supplied by Murdoch University, Murdoch 6150, Western Australia and the Division of Water Technology, CSIR, PO Box 395, Pretoria, South 15 Africa.

Ohlinger, K.N., Young, T.M. and Schroeder, E.D. (1998) Predicting struvite formation in digestion. Water Research 32 (12), 3607-3614.

20 Parsons, S.A. and Doyle, J.D. (2004) Struvite scale formation and control. Water Science and Technology 49 (2), 177-182.

Pastor, L., Martí, N., Bouzas, A. and Seco, A. (2007) Sewage sludge management for phosphorus recovery as struvite in EBPR wastewater treatment plants. Bioresource 25 Tecnology 99 (11), 4817-4824. 
Plant, L.J. and House, W.A. (2002) Precipitation of calcite in the presence of inorganic phosphate. Colloids and Surfaces A: Physicochemical and Engineering Aspects, 203 (1-3), 143-153.

5

Schuiling, R.D. and Andrade, A. (1999) Recovery of struvite from calf manure. Environmental Technology 20 (7), 765-768.

Taylor, A.W., Frazier, A.W., Gurney, E.L. (1963) Trans. Faraday Soc. 59, 1580-1584. 10

Wild, D., Kisliakova, A. and Siegrist, H. (1997) Prediction of recycle phosphorus loads from anaerobic digestion. Water Research 31 (9), 2300-2308.

Wilsenach, J., Schuurbiers, C.A.H. and van Loosdrecht, M.C.M. (2006) Phosphate and 15 potassium recovery from source separated urine through struvite precipitation. Water Research 41 (2), 458-466.

Zhao, H.W. and Viraraghavan, T. (2004) Analysis of the performance of an anaerobic digestion system at the Regina wastewater treatment plant. Bioresource Technology 95 (3), 301-307. 
Table 1 - Operational characteristics of the configurations tested

\begin{tabular}{ccccc}
\hline Configuration & $\begin{array}{c}\text { Sludge } \\
\text { thickening }\end{array}$ & Elutriation & $\begin{array}{c}\text { Secondary } \\
\text { sludge settling }\end{array}$ & $\begin{array}{c}\text { Contact } \\
\text { tank }\end{array}$ \\
\hline C1 & separated & no & no & no \\
C2 & mixed & yes & yes & no \\
C3 & mixed & no & yes & yes \\
C4 & mixed & yes & no & no \\
\hline
\end{tabular}


Table 2 - Operational parameters and digestion process results

\begin{tabular}{|c|c|c|c|c|c|c|c|c|c|c|c|c|c|c|c|c|c|}
\hline \multicolumn{2}{|c|}{ Operational parameters } & \multicolumn{4}{|c|}{ C1 } & & \multirow{2}{*}{\multicolumn{4}{|c|}{$\begin{array}{c}\text { C3 } \\
8\end{array}$}} & \\
\hline & $\left(\mathrm{l} \mathrm{d}^{-1}\right)$ & \multicolumn{4}{|c|}{6.75} & \multicolumn{4}{|c|}{6.75} & & & & & \multicolumn{4}{|c|}{4.25} \\
\hline MP & $\left(\mathrm{W} \mathrm{l}^{-1}\right)$ & \multicolumn{4}{|c|}{0.11} & \multicolumn{4}{|c|}{0.11} & \multicolumn{4}{|c|}{$\begin{array}{c}8 \\
0.09\end{array}$} & \multicolumn{4}{|c|}{0.36} \\
\hline OLR & $\left(\mathrm{kg} \mathrm{COD} \mathrm{l}^{-1} \mathrm{~d}^{-1}\right)$ & \multicolumn{4}{|c|}{2.03} & \multicolumn{4}{|c|}{1.44} & \multicolumn{4}{|c|}{1.4} & \multicolumn{4}{|c|}{1.8} \\
\hline $\mathrm{m}$ & $\left(\mathrm{kg} \mathrm{SST} \mathrm{d}^{-1}\right)$ & \multicolumn{4}{|c|}{0.251} & \multicolumn{4}{|c|}{0.293} & \multicolumn{4}{|c|}{0.283} & \multicolumn{4}{|c|}{0.166} \\
\hline \%PPS & (\%) & \multicolumn{4}{|c|}{51} & \multicolumn{4}{|c|}{33} & \multicolumn{4}{|c|}{65} & \multirow{2}{*}{\multicolumn{4}{|c|}{$\begin{array}{l}45 \\
55\end{array}$}} \\
\hline \%EBPR & (\%) & \multicolumn{4}{|c|}{49} & \multicolumn{4}{|c|}{67} & \multicolumn{4}{|c|}{35} & & & & \\
\hline & & Influ & lent & Effl & uent & Infl & uent & Effl & lent & Influ & uent & Efflt & uent & Influ & uent & Efflu & ient \\
\hline Sludge ch & rization & average & s.d. & average & s.d. & average & s.d. & average & s.d. & average & s.d. & average & s.d. & average & s.d. & average & s.d. \\
\hline TS & $\left(\mathrm{mg} \mathrm{l}^{-1}\right)$ & 37257 & \pm 8444 & 18554 & \pm 3224 & 26671 & \pm 3516 & 17619 & \pm 2616 & 26085 & \pm 5887 & 16736 & \pm 659 & 29583 & \pm 3138 & 16850 & \pm 3905 \\
\hline TVS & $\left(\mathrm{mg} \mathrm{l}^{-1}\right)$ & 23194 & \pm 4403 & 10484 & \pm 1683 & 18734 & \pm 2517 & 10848 & \pm 1632 & 18206 & \pm 4164 & 9764 & \pm 352 & 18637 & \pm 1859 & 7545 & \pm 1835 \\
\hline TVS & (\%) & 64 & \pm 7 & 56 & \pm 3 & 69 & \pm 1 & 62 & \pm 1 & 70 & \pm 6 & 58 & \pm 1 & 63 & \pm 4 & 45 & \pm 1 \\
\hline TCOD & $\left(\mathrm{mgO}_{2} \mathrm{l}^{-1}\right)$ & 40650 & \pm 8129 & 16660 & \pm 2623 & 28875 & \pm 4221 & 15975 & \pm 1995 & 28514 & \pm 4372 & 13482 & \pm 722 & 32650 & \pm 1314 & 11076 & \pm 1166 \\
\hline $\mathrm{TP}$ & $\left(\mathrm{mg} \mathrm{l}^{-1}\right)$ & 1020 & \pm 102 & 985 & \pm 22 & 981 & \pm 126 & 902 & \pm 145 & 730 & \pm 147.1 & 687 & \pm 100.4 & 577 & \pm 20.4 & 443 & \pm 46.9 \\
\hline $\mathrm{PO}_{4}-\mathrm{P}$ & $\left(\mathrm{mg} \mathrm{l}^{-1}\right)$ & 70.7 & \pm 19.8 & 152.2 & \pm 25.8 & 253.7 & \pm 67.4 & 201.4 & \pm 28.1 & 109.1 & \pm 25.1 & 69.1 & \pm 11.05 & 98.6 & \pm 24.1 & 67.6 & \pm 14.3 \\
\hline $\mathrm{NH}_{4}-\mathrm{N}$ & $\left(\mathrm{mg} \mathrm{l}^{-1}\right)$ & 104.1 & \pm 51.8 & 617.4 & \pm 60.6 & 69.0 & \pm 35.0 & 580.0 & \pm 81.1 & 126.3 & \pm 46.9 & 651.4 & \pm 26.2 & 110.6 & \pm 18.9 & 796.0 & \pm 68.2 \\
\hline $\mathrm{pH}$ & & 6.4 & \pm 0.1 & 7.0 & \pm 0.1 & 6.1 & \pm 0.1 & 7.0 & \pm 0.2 & 6.2 & \pm 0.1 & 6.9 & \pm 0.1 & 6.2 & \pm 0.1 & 7.2 & \pm 0.1 \\
\hline $\mathrm{ALK}_{\mathrm{P}}$ & $\left(\mathrm{mgCaCO}_{3 .} \mathrm{l}^{-1}\right)$ & 407 & \pm 106 & 2381 & \pm 371 & 414 & \pm 105 & 2308 & \pm 307 & 523 & \pm 127 & 2069 & \pm 482 & 397 & \pm 105 & 2245 & \pm 330 \\
\hline ALKVFA & & --- & --- & 0.10 & \pm 0.02 & --- & --- & 0.11 & \pm 0.02 & --- & --- & 0.24 & \pm 0.03 & --- & --- & 0.20 & \pm 0.02 \\
\hline $\mathrm{K}^{+}$ & $\left(\mathrm{mg} \mathrm{l}^{-1}\right)$ & 71.8 & \pm 23.6 & 237.4 & \pm 13.2 & 160.2 & \pm 39.9 & 258.6 & \pm 30.3 & 100.4 & \pm 19.1 & 179.8 & \pm 59.0 & 65.9 & \pm 20.3 & 132.6 & \pm 6.2 \\
\hline $\mathrm{Mg}^{2+}$ & $\left(\mathrm{mg} \mathrm{l}^{-1}\right)$ & 60.2 & \pm 14.8 & 11.9 & \pm 5.8 & 113.5 & \pm 29.9 & 26.1 & \pm 9.2 & 72.8 & \pm 6.1 & 62.8 & \pm 5.2 & 72.3 & \pm 9.1 & 40.4 & \pm 9.5 \\
\hline $\mathrm{Ca}^{2+}$ & $\left(\mathrm{mg} \mathrm{l}^{-1}\right)$ & 151.3 & \pm 20.9 & 49.8 & \pm 18.6 & 104.9 & \pm 19.9 & 40.8 & \pm 7.6 & 123.1 & \pm 12.3 & 70.5 & \pm 10.8 & 124.7 & \pm 23.6 & 57.0 & \pm 10.7 \\
\hline Anaerobi & tion results & & & & & & & & & & & & & & & & \\
\hline $\mathrm{TCOD}_{\mathrm{rem}}$ & (\%) & & 59 & .0 & & & 44 & & & & 52 & & & & 66 & & \\
\hline TVS $_{\text {rem }}$ & (\%) & & 54 & & & & 42 & & & & 46 & & & & 59 & & \\
\hline
\end{tabular}


Table 3 - Precipitation results in the anaerobic digester

\begin{tabular}{lcccc}
\hline Parameter $\left(\mathrm{mg} \mathrm{l}^{-1}\right)$ & \multicolumn{4}{c}{ Configuration } \\
\hline$K_{\text {TOTrel }}$ & $\mathrm{C} 1$ & $\mathrm{C} 2$ & $\mathrm{C} 3$ & $\mathrm{C} 4$ \\
\cline { 2 - 5 } KoRGrel & 165.6 & 98.5 & 79.4 & 66.7 \\
K$_{\text {PAOrel }}$ & 67.8 & 49.7 & 39.0 & 62.8 \\
P $_{\text {PAOrel }}$ & 97.8 & 48.7 & 40.4 & 3.9 \\
PORGrel $_{\text {POTrel }}$ & 276.3 & 137.7 & 114.1 & 11.1 \\
$\mathrm{P}_{\text {av }}$ & 208.6 & 139.7 & 130.5 & 186.9 \\
$\mathrm{P}_{\text {fix }}$ & 484.9 & 277.4 & 244.5 & 198.0 \\
Mg $_{\text {PAOrel }}$ & 555.6 & 531.1 & 353.7 & 296.6 \\
MgORGrel $_{\text {Mg }}$ & 403.4 & 329.7 & 284.6 & 229.0 \\
Mg $_{\text {prec }}$ & 78.2 & 39.0 & 32.3 & 3.1 \\
Ca $_{\text {libORG }}$ & 57.4 & 34.1 & 39.3 & 49.4 \\
Ca $_{\text {prec }}$ & 135.5 & 73.1 & 71.5 & 52.5 \\
\hline
\end{tabular}


Table 4 - Fixed phosphorus distribution and ion molar ratios in the digester

\begin{tabular}{lcccc}
\cline { 2 - 5 } & $\mathrm{C} 1$ & $\mathrm{C} 2$ & $\mathrm{C} 3$ & $\mathrm{C} 4$ \\
\hline \%P-MAP & 58.1 & 62.0 & 36.5 & 38.1 \\
\%P-HAP & 14.5 & 12.0 & 10.5 & 18.6 \\
\%P-ads & 27.4 & 25.9 & 53.0 & 43.3 \\
\hline $\mathrm{Mg} / \mathrm{P}$ & 0.45 & 0.45 & 0.52 & 0.54 \\
$\mathrm{Mg} / \mathrm{Ca}$ & 1.83 & 2.44 & 1.76 & 1.38 \\
$\mathrm{Ca} / \mathrm{P}$ & 0.24 & 0.18 & 0.29 & 0.39 \\
\hline
\end{tabular}


Table 5 - Saturation Index (SI) values at the digester conditions

\begin{tabular}{lclcccc}
\hline Mineral & $\mathrm{pK}_{\mathrm{ps}}$ & Reference & \multicolumn{3}{c}{ SI } \\
\cline { 3 - 6 } & & & $\mathrm{C} 1$ & $\mathrm{C} 2$ & $\mathrm{C} 3$ & $\mathrm{C} 4$ \\
\hline Struvite (MAP) & 13.3 & Ohlinger et al. (1998) & 1.462 & 1.288 & 1.142 & 0.968 \\
Hydroxyapatite (HAP) & 48.6 & Murray and May (1996) & 12.497 & 12.589 & 11.199 & 11.253 \\
Amorphous calcium phosphate (ACP) & 24.0 & Mamais et al. (1994) & 4.024 & 4.011 & 3.123 & 3.331 \\
Potassium struvite & 10.6 & Taylor et al. (1963) & -2.389 & -2.746 & -2.474 & -2.851 \\
\hline
\end{tabular}


Table 6 - Characteristics of the P-rich streams produced

\begin{tabular}{lcccccccc}
\hline & \multicolumn{4}{c}{ Thickener supernatant } & \multicolumn{4}{c}{ Dewatering centrate } \\
\cline { 2 - 8 } & $\mathrm{C} 1$ & $\mathrm{C} 2$ & $\mathrm{C} 3$ & $\mathrm{C} 4$ & $\mathrm{C} 1$ & $\mathrm{C} 2$ & $\mathrm{C} 3$ & $\mathrm{C} 4$ \\
\cline { 2 - 8 } $\mathrm{Q}\left(\mathrm{l} \mathrm{d}^{-1}\right)$ & $41.3 \pm 3$ & $5.3 \pm 0.4$ & $2.0 \pm 0.2$ & $43.8 \pm 4$ & $4.5 \pm 0.2$ & $4.5 \pm 0.2$ & $5.3 \pm 0.3$ & $2.8 \pm 0.1$ \\
$\mathrm{PO}_{4}-\mathrm{P}\left(\mathrm{mg} \mathrm{l}^{-1}\right)$ & $11.3 \pm 2.3$ & $127.0 \pm 23.3$ & $79.8 \pm 22.3$ & $46.5 \pm 11.6$ & $152.2 \pm 18.2$ & $201.4 \pm 23.4$ & $69.1 \pm 7.6$ & $67.6 \pm 8.3$ \\
\hline
\end{tabular}


Table 7 - Phosphorus recovery assessment

\begin{tabular}{lcccc}
\hline & C1 & C2 & C3 & C4 \\
\cline { 2 - 5 } WP LOST (gP kg sludge $^{-1}$ ) & & & & \\
Thickener supernatant & 1.9 & 0 & 0 & 0 \\
Precipitation in digester & 10.8 & 7.6 & 8 & 5.8 \\
Dewatered sludge & 1.4 & 1.5 & 0.7 & 0.6 \\
Total & 14.1 & 9.1 & 8.7 & 6.4 \\
\hline wP Av (gP kg sludge & -1) & & & \\
Thickener supernatant & 0 & 2.3 & 0.6 & 12.3 \\
Dewatering centrate & 2.7 & 3.1 & 1.3 & 1.2 \\
Total & 2.7 & 5.4 & 1.9 & 13.5 \\
\hline wP Tot (gP kg sludge $^{-\mathbf{1}}$ ) & 16.8 & 14.5 & 10.6 & 19.9 \\
\hline Potential Phosphorus (\%) & 16 & 37 & 18 & 68 \\
\hline
\end{tabular}


Table 8 - Crystallizer inlet stream molar ratios

\begin{tabular}{lcccc}
\hline & C1 & C2 & C3 & C4 \\
\cline { 2 - 5 } $\mathrm{Mg} / \mathrm{Ca}$ & 0.39 & 1.67 & 1.35 & 0.61 \\
$\mathrm{Mg} / \mathrm{P}$ & 0.10 & 0.43 & 1.12 & 1.50 \\
$\mathrm{Ca} / \mathrm{P}$ & 0.25 & 0.25 & 0.83 & 2.45 \\
\hline
\end{tabular}




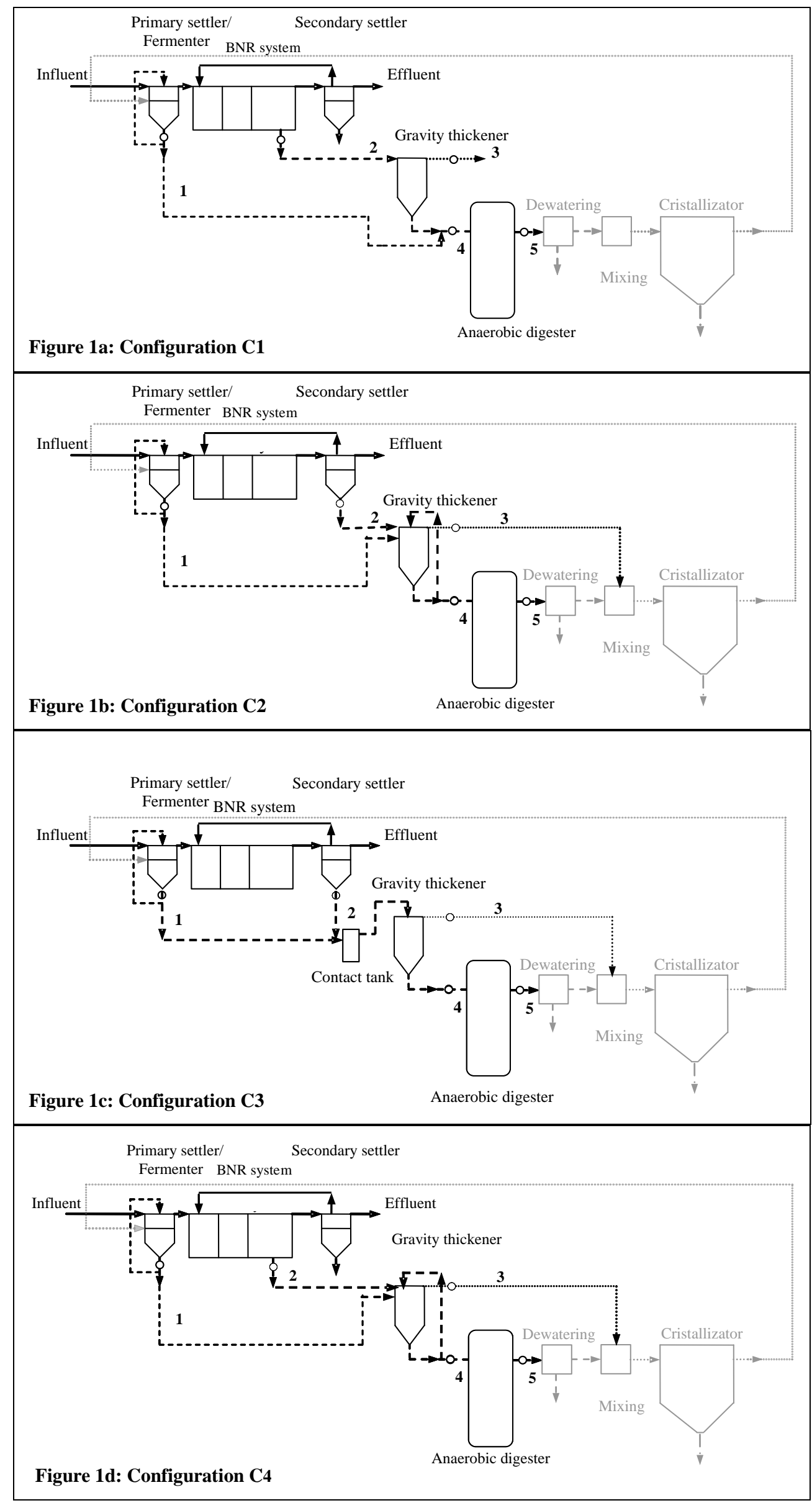

Grey lines: processes not studied in this work $\circ$ Sampling points

Figure 1 - Layout of the four pilot plant configurations 


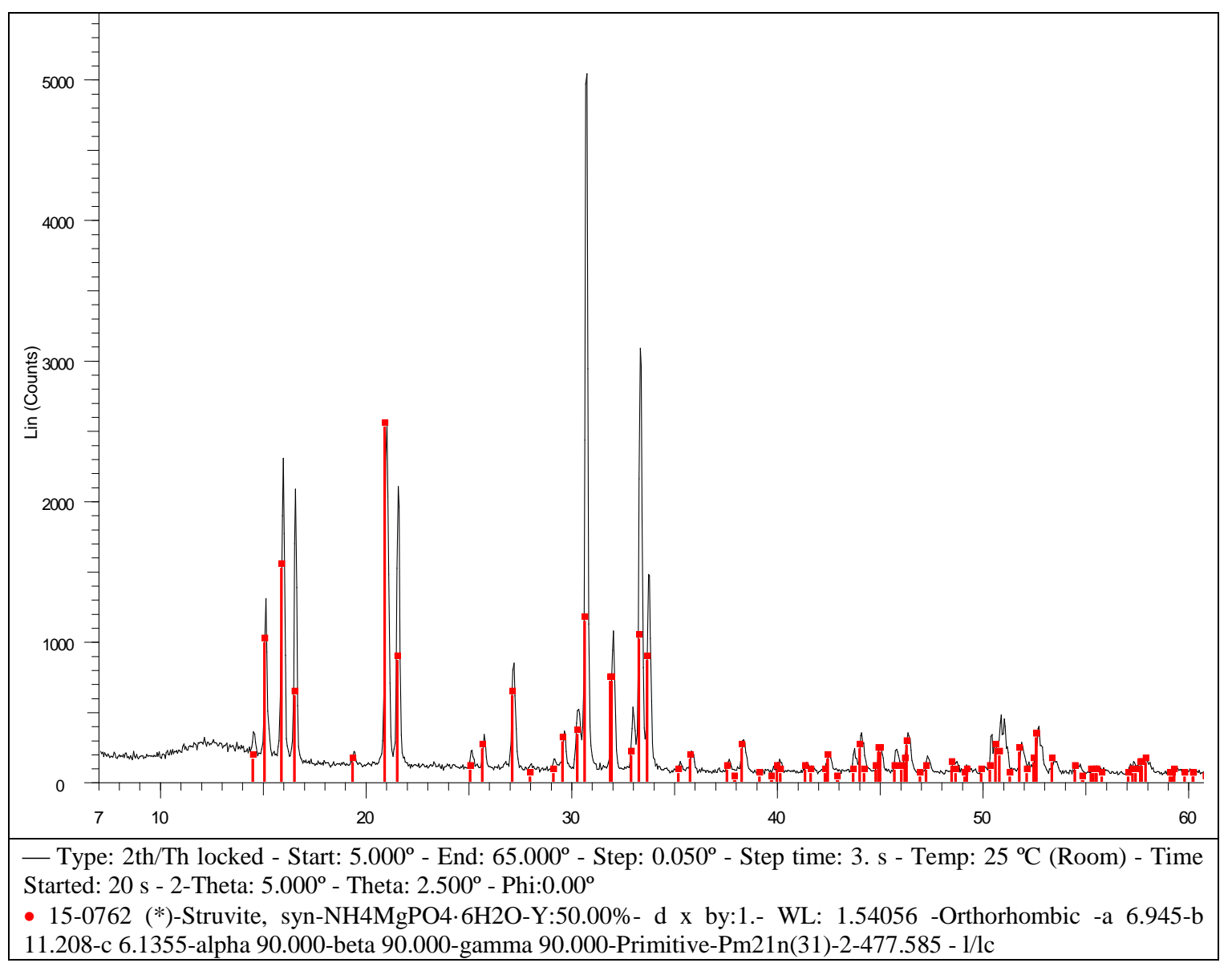

Fig. 2 - XRD analysis for a solid deposit found in the outgoing digester pipe. 